\title{
Does self-report of multimorbidity in later life predict impaired physical functioning, and might this be useful in clinical practice?
}

\author{
Michael A. Clynes ${ }^{1} \cdot$ Gregorio Bevilacqua $^{1} \cdot$ Karen A. Jameson ${ }^{1} \cdot$ Cyrus Cooper ${ }^{1,2}$ - Elaine M. Dennison ${ }^{1,3}$ (D)
}

Received: 16 January 2020 / Accepted: 28 January 2020 / Published online: 13 February 2020

(c) The Author(s) 2020

\begin{abstract}
Background Multimorbidity has been shown in several studies to relate to impaired physical function in later life.

Aims To examine if self-report of multimorbidity predicts impaired physical functioning, as assessed by formal physical function testing, in community-dwelling older adults.

Methods Non-communicable diseases (NCDs) were self-reported by 443 older community-dwelling UK adults via questionnaire, asking the question: 'Have you been told by a doctor that you have any of the following conditions?' Assessments of walking speed, chair stands and balance allowed us to create a composite score (0-12) on which impaired physical functioning was defined as $\leq 9$.

Results The mean age of participants was $75.5 \pm 2.5$ years for men and $75.8 \pm 2.6$ for women. The proportion of individuals with impaired physical functioning was $71.2 \%$ in women and $56.9 \%$ in men. Having four or more NCDs was associated with an increased risk of poor physical function in men and women $(p<0.05)$. The number of medications and medicated systems was associated with gait speed $(p<0.03$ and $<0.02$, respectively) and timed up-and-go tests $(p<0.03$ and $<0.02$, respectively) in women but not men.

Discussion and conclusion Self-report of 4 or more NCDs was associated with an increased risk of poor physical function, an outcome which has previously been associated with adverse clinical sequelae. This observation may inform development of a simple screening tool to look for poor physical function in older adults.
\end{abstract}

Keywords Ageing $\cdot$ Multimorbidity $\cdot$ Non-communicable diseases $\cdot$ Older people $\cdot$ Physical functioning

\section{Introduction}

An increase in life-expectancy and a subsequent ageing population have led to a higher prevalence of chronic, noncommunicable diseases (NCDs) [1]. These chronic diseases contribute to a substantially increased risk of morbidity and mortality in older people [2]. The number of NCDs rises substantially with age [3]; a study by Bayliss and colleagues, utilising a survey of members of a health maintenance organisation aged 65 and over, found the average person had 8.7 chronic diseases [4] while another Canadian study reported the number of chronic diseases varies from 2.8 in young patients to 6.4 among older patients [5].

Reduced physical functioning in later life has personal and societal impacts, with an increased propensity to fall, and inability to self-care [6,7]. Physical functioning tests are widely used tools in the research setting for exploring the reduction of physical functioning in older persons, and are part of the assessment for a diagnosis of sarcopenia 
$[8,9]$. Studies have linked poor performance in these tests with nursing home and hospital admissions [10, 11]. Furthermore, impaired physical functioning in such tests may predict falls and fracture risk [6, 7]. However, adoption in clinical practice is difficult due to time and space constraints.

Individual NCDs have been shown in several studies to relate to impaired physical functioning [3, 4, 12]. Other researchers have suggested that the number of NCDs might be useful as a screening tool for predicting reduced physical functioning in older adults [13]. However, most studies have been undertaken in populations drawn from secondary care $[14,15]$ or frailer elderly $[16,17]$.

In the current study we therefore sought to explore, in a cohort of community-dwelling older adults in the UK, whether self-report of number of NCDs, medications, and medicated systems predicted poor physical functioning in such a population. If this was the case, it might be useful to clinicians caring for older community-dwelling adults as a simple way of identifying those at risk of poor physical function and associated clinical sequelae, and lead to the development of a simple screening tool for poor physical functioning.

\section{Methods}

Participants were recruited from the Hertfordshire Cohort Study (HCS), a population-based sample of men and women born during 1931-1939 in Hertfordshire. Subjects were visited at home by a trained nurse, who administered a lifestyle questionnaire. The visits also included measurements of height and weight to calculate body mass index (BMI) and the identification of a number of NCDs and the medications participants were taking.

NCDs were self-reported by participants via questionnaire, asking the question: 'Have you been told by a doctor that you have any of the following conditions?'. The following NCDs were recorded: hypertension, heart disease, stroke, diabetes, lung disease, thyroid disease, rheumatoid arthritis, osteoarthritis, multiple sclerosis, vitiligo, depression, Parkinson's disease, peripheral arterial disease, osteoporosis and cancer (Supplementary Table 2). Participants were also asked to list other significant medical conditions, but few participants had any other individualised concerns. No participants were recruited with known dementia or cognitive impairment.

Smoker status was categorised as never smoked, exsmoker or current smoker depending on the participants' answers to the questions "Have you ever smoked regularly?" and "Do you still smoke regularly?". Participants were asked how often they currently drank different types of alcohol (beer, wine, spirits, etc.) and how much they normally drank each time. This was used to estimate their alcohol consumption in units per week.
Participants were asked for details of any medications they were currently taking. These were grouped according to the system medicated: cardiovascular, respiratory, gastrointestinal, endocrine, central nervous system, malignant disease and immunosuppression, nutrition and blood, musculoskeletal and joint disease, eye, ear, nose, skin, genito-urinary tract and miscellaneous.

The physical functioning score was derived from tests of gait speed, chair rises, and balance. To test walking speed, an 8 foot course, with no obstructions for an additional foot at either end, was marked out on the floor. Participants were asked to walk at their customary pace and the time taken was recorded using a stopwatch. The use of assistive devices, such as canes, was permitted if required. Gait speed was determined by dividing the distance traversed by the time between the first and last step.

In the timed up-and-go test, participants were asked to rise from a chair, walk $3 \mathrm{~m}$, turn around, walk back to the chair and sit down again. The use of mobility aids was permitted if required. Time taken was recorded using a stopwatch.

To test chair rises, participants crossed their arms across their chest and stood up. Those who could complete this task were asked to stand up and sit down again a total of five times. The time was taken from their initial sitting position until they were standing on the fifth repetition.

The tandem stands tested the participants' ability to maintain their balance. The standing balance test involved a semitandem stand where participants placed one foot in front of the other such that the big toe of one foot was touching the side of the heel of the other. If participants could not hold the semi-tandem stand for $10 \mathrm{~s}$, they did a side-by-side stand (standing with the feet side-by-side). If they could hold the semi-tandem stand for $10 \mathrm{~s}$, they also attempted a full tandem stand where participants placed one foot in front of the other (touching heel to toe) and held this position for as long as they could up to $10 \mathrm{~s}$.

For the walking test and chair stands, those who could not complete the test were given a score of 0 . The remaining participants' times were divided into quartiles and given a score of $1-4$, slowest to fastest quartile. For the balance test, if the participant maintained balance in the full tandem stand for $10 \mathrm{~s}$, they were given a score of 4 ; if they obtained a time $\geq 3$ and $<10 \mathrm{~s}$, they scored 3 ; if they obtained a time of less than $3 \mathrm{~s}$ but were able to maintain a semi-tandem stand, they scored 2; if they could not do the semi-tandem stand but could do the side-by-side stand, they scored 1; and if they could not do either the semi-tandem or the side-by-side stand, they scored 0 . The scores for the walking test, chair rises and balance test were then summed. The maximum possible score was 12 and the minimum was 0 . In keeping with previous work, those with a score equal to or lower than 9 were designated as having impaired physical functioning $[18,19]$. 
Table 1 Baseline characteristics of study participants, physical functioning, NCDs, medications and medicated systems, by sex

\begin{tabular}{|c|c|c|c|c|c|c|c|}
\hline \multirow[t]{2}{*}{ Participants' characteristics } & \multicolumn{3}{|l|}{ Men } & \multicolumn{3}{|l|}{ Women } & \multirow[t]{2}{*}{$p$-value } \\
\hline & $N$ & Mean & SD & $N$ & Mean & SD & \\
\hline Age (years) & 222 & 75.5 & 2.5 & 221 & 75.8 & 2.6 & 0.280 \\
\hline \multirow[t]{2}{*}{ Height $(\mathrm{cm})$} & 221 & 172.7 & 6.5 & 217 & 158.8 & 6.1 & $<0.001$ \\
\hline & $N$ & Median & IQR & $N$ & Median & IQR & \\
\hline Weight (kg) & 221 & 81.7 & $74.5-89.4$ & 221 & 70.0 & $62.2-79.1$ & $<0.001$ \\
\hline BMI $\left(\mathrm{kg} / \mathrm{m}^{2}\right)$ & 221 & 27.4 & $25.3-29.9$ & 217 & 27.5 & $24.6-31.6$ & 0.409 \\
\hline Activity time in last 2 weeks ( $\mathrm{min} /$ day) & 205 & 176 & $105-270$ & 210 & 200 & $135-283$ & 0.089 \\
\hline \multirow[t]{2}{*}{ Alcohol consumption (units per week) } & 222 & 6.5 & $1.0-14.0$ & 221 & 0.5 & $0.0-3.5$ & $<0.001$ \\
\hline & Total $N$ & $N$ & $\%$ & Total $N$ & $N$ & $\%$ & \\
\hline Smoker status & 222 & & & 221 & & & $<0.001$ \\
\hline Never smoked & & 85 & 38.3 & & 142 & 64.3 & \\
\hline Ex-smoker & & 126 & 56.8 & & 73 & 33.0 & \\
\hline Current smoker & & 11 & 5.0 & & 6 & 2.7 & \\
\hline Social class & 211 & & & 221 & & & 0.520 \\
\hline I-IIINM & & 89 & 42.2 & & 100 & 45.2 & \\
\hline IIIM-V & & 122 & 57.8 & & 121 & 54.8 & \\
\hline \multicolumn{8}{|l|}{ Physical functioning } \\
\hline & $N$ & Mean & SD & $N$ & Mean & SD & \\
\hline \multirow[t]{2}{*}{ Gait speed $(\mathrm{m} / \mathrm{s})$} & 207 & 0.78 & 0.17 & & 0.73 & 0.18 & 0.006 \\
\hline & Total N & $N$ & $\%$ & & $N$ & $\%$ & \\
\hline \multirow[t]{2}{*}{ Tandem stand $<10 \mathrm{~s}$} & 214 & 43 & 20.1 & 213 & 56 & 26.3 & 0.129 \\
\hline & $N$ & Median & IQR & $N$ & Median & IQR & \\
\hline $6 \mathrm{~m}$ timed up-and-go (sec) & 203 & 11.2 & $10.0-13.1$ & 203 & 11.8 & $10.0-14.0$ & 0.138 \\
\hline Chair rises $(\mathrm{sec})$ & 196 & 15.8 & $13.6-18.8$ & 187 & 17 & $13.8-20.2$ & 0.049 \\
\hline \multirow[t]{2}{*}{ Physical functioning score } & 204 & 9.0 & $7.0-11.0$ & 198 & 8.0 & $7.0-10.0$ & 0.003 \\
\hline & Total $N$ & $N$ & $\%$ & Total $N$ & $N$ & $\%$ & \\
\hline Low physical functioning score $(<=9)$ & 204 & 116 & 56.9 & 198 & 141 & 71.2 & 0.003 \\
\hline \multicolumn{8}{|l|}{ Self-reported NCDs } \\
\hline & Total $N$ & $N$ & $\%$ & Total $N$ & $N$ & $\%$ & \\
\hline Hypertension & 222 & 109 & 49.1 & 221 & 101 & 45.7 & 0.474 \\
\hline Heart disease & 222 & 55 & 24.8 & 221 & 34 & 15.4 & 0.014 \\
\hline Stroke & 222 & 13 & 5.9 & 221 & 12 & 5.4 & 0.846 \\
\hline Diabetes & 222 & 36 & 16.2 & 221 & 24 & 10.9 & 0.099 \\
\hline Lung disease & 222 & 30 & 13.5 & 221 & 31 & 14.0 & 0.875 \\
\hline Thyroid disease & 222 & 14 & 6.3 & 221 & 29 & 13.1 & 0.015 \\
\hline Rheumatoid arthritis & 222 & 10 & 4.5 & 221 & 11 & 5.0 & 0.815 \\
\hline Osteoarthritis & 222 & 75 & 33.8 & 221 & 96 & 43.4 & 0.037 \\
\hline \multicolumn{8}{|l|}{ NCDs, medications, and medicated systems } \\
\hline & $N$ & Median & IQR & $N$ & Median & IQR & \\
\hline Number of NCDs & 222 & 1 & $1.0-2.0$ & 221 & 1 & $0.0-2.0$ & 0.939 \\
\hline Number of medications & 222 & 4.5 & $2.0-6.0$ & 221 & 4 & $2.0-7.0$ & 0.799 \\
\hline \multirow[t]{2}{*}{ Number of systems medicated } & 222 & 2 & $1.0-4.0$ & 221 & 3 & $2.0-4.0$ & 0.079 \\
\hline & Total $N$ & $N$ & $\%$ & Total $N$ & $N$ & $\%$ & \\
\hline Number of NCDs & 222 & & & 221 & & & 0.125 \\
\hline
\end{tabular}


Table 1 (continued)

\begin{tabular}{|c|c|c|c|c|c|c|c|}
\hline & Total $N$ & $N$ & $\%$ & Total $N$ & $N$ & $\%$ & \\
\hline 0 & & 41 & 18.5 & & 56 & 25.3 & \\
\hline 1 & & 80 & 36.0 & & 61 & 27.6 & \\
\hline 2 & & 61 & 27.5 & & 52 & 23.5 & \\
\hline 3 & & 21 & 9.5 & & 26 & 11.8 & \\
\hline 4 or more & & 19 & 8.6 & & 26 & 11.8 & \\
\hline Number of medications & 222 & & & 221 & & & 0.384 \\
\hline 0 & & 17 & 7.7 & & 13 & 5.9 & \\
\hline $1-2$ & & 42 & 18.9 & & 53 & 24.0 & \\
\hline $3-5$ & & 84 & 37.8 & & 71 & 32.1 & \\
\hline 6 or more & & 79 & 35.6 & & 84 & 38.0 & \\
\hline Number of systems medicated & 222 & & & 221 & & & 0.484 \\
\hline 0 & & 17 & 7.7 & & 13 & 5.9 & \\
\hline 1 & & 50 & 22.5 & & 41 & 18.6 & \\
\hline 2 & & 56 & 25.2 & & 50 & 22.6 & \\
\hline 3 & & 36 & 16.2 & & 46 & 20.8 & \\
\hline 4 or more & & 63 & 28.4 & & 71 & 32.1 & \\
\hline
\end{tabular}

\section{Statistical analysis}

The physical functioning outcomes were assessed for normality and transformed where necessary using the FisherYates rank-based inverse normal transformation to produce z-scores. Descriptive statistics for continuous variables were expressed as mean and standard deviation (SD) or median and interquartile range (IQR) as appropriate. Categorical variables were expressed as frequency and percentage. Differences between men and women were assessed using Student's $t$ tests, Mann-Whitney tests or Pearson's $\chi^{2}$ tests, as appropriate. Linear and logistic regression analyses were used to examine the associations between the number of NCDs, medications and systems medicated and physical functioning outcomes. The regression analyses were undertaken with and without adjusting for the following demographic and lifestyle confounders: age, BMI, smoker status, alcohol consumption and social class. The results of the regression analyses are presented as regression coefficients $(\beta)$ or odds ratios (OR) and $95 \%$ confidence intervals $(\mathrm{CI})$. A $p$-value of $\leq 0.05$ was considered to be statistically significant. The analyses were conducted using Stata version 14 .

\section{Results}

Table 1 displays baseline characteristics of the participants. We explored the impact of number of NCDs on physical functioning (Table 2). In both sexes having up to three NCDs, did not significantly impact physical functioning as assessed by all measures, with the exception of chair rises in women where having $3 \mathrm{NCDs}$ was associated with impaired chair rises $(\beta 0.54,95 \%$ CI $0.05,1.04 p=0.032)$. In both men and women, however, self-reported 4 or more NCDs were associated with impaired timed up-and-go (men: $\beta 1.00,95 \%$ CI $0.45,1.56 p<0.01$; women: $\beta 0.90$, 95\% CI 0.46, $1.34 p<0.01$ ), chair rises (men: $\beta 1.43$, 95\% CI $0.82,2.03 p<0.01$; women: $\beta 0.99,95 \%$ CI $0.48,1.51$ $p<0.01$ ) and physical functioning score (men: $\beta-1.01$, 95\% CI $-1.64,-0.37 p<0.01$; women: $\beta-0.59,95 \%$ CI $-1.12,-0.06 p=0.029)$. Having 4 or more NCDs was also associated with reduced gait speed in women $(\beta-0.46$, $95 \% \mathrm{CI}-0.91,-0.01 p=0.047)$ and impaired tandem stand in men (OR 5.49, 95\% CI 1.43, $21.01 p=0.013)$.

Polypharmacy is common in individuals with multimorbidity; we thus explored whether there were any associations between the number of medications an individual takes and physical functioning (see Table 3). In men there was no significant association between the number of medications taken and all our recorded measures of physical functioning. Conversely, in women there was a significant association between taking 6 or more medications and impaired gait speed $(\beta-0.61,95 \% \mathrm{CI}-1.13,0.09 p=0.021)$ and timed up-and-go $(\beta 0.62,95 \%$ CI $0.10,1.15 p=0.021)$. We observed similar results when looking at the number of systems medicated (see Supplementary Table 1).

\section{Discussion}

The aim of this study was to examine associations between the number of self-reported NCDs, medications and medicated systems with physical function tests in men and women. We found that the proportion of individuals with a 
Table 2 Number of NCDs (categorical) as an explanatory variable for physical functioning outcomes, by sex

\begin{tabular}{|c|c|c|c|c|c|c|c|c|}
\hline & \multicolumn{4}{|c|}{ Men } & \multicolumn{4}{|c|}{ Women } \\
\hline & $N$ & $\begin{array}{l}\text { Regression } \\
\text { coefficient }\end{array}$ & $95 \% \mathrm{CI}$ & $p$-value & $N$ & $\begin{array}{l}\text { Regression } \\
\text { coefficient }\end{array}$ & $95 \% \mathrm{CI}$ & $p$-value \\
\hline Gait speed (FY z-score) & 196 & & & & 202 & & & \\
\hline 1 NCDs & & -0.01 & $(-0.38,0.36)$ & 0.968 & & -0.14 & $(-0.49,0.20)$ & 0.408 \\
\hline 2 NCDs & & 0.17 & $(-0.23,0.57)$ & 0.397 & & -0.26 & $(-0.62,0.10)$ & 0.15 \\
\hline 3 NCDs & & 0.05 & $(-0.50,0.59)$ & 0.870 & & -0.21 & $(-0.68,0.27)$ & 0.395 \\
\hline 4 or more NCDs & & -0.54 & $(-1.11,0.04)$ & 0.068 & & -0.46 & $(-0.91,-0.01)$ & 0.047 \\
\hline Timed up-and-go (FY z-score) & 192 & & & & 200 & & & \\
\hline $1 \mathrm{NCDs}$ & & -0.03 & $(-0.36,0.31)$ & 0.869 & & 0.13 & $(-0.20,0.46)$ & 0.453 \\
\hline 2 NCDs & & -0.09 & $(-0.46,0.27)$ & 0.606 & & 0.20 & $(-0.14,0.54)$ & 0.242 \\
\hline 3 NCDs & & 0.47 & $(-0.03,0.98)$ & 0.066 & & 0.28 & $(-0.17,0.73)$ & 0.225 \\
\hline 4 or more NCDs & & 1.00 & $(0.45,1.56)$ & $<0.001$ & & 0.90 & $(0.46,1.34)$ & $<0.001$ \\
\hline Chair rises (FY $z$-score) & 185 & & & & 185 & & & \\
\hline 1 NCDs & & 0.02 & $(-0.34,0.38)$ & 0.916 & & 0.00 & $(-0.36,0.36)$ & 0.981 \\
\hline 2 NCDs & & 0.18 & $(-0.21,0.56)$ & 0.361 & & 0.07 & $(-0.32,0.46)$ & 0.713 \\
\hline 3 NCDs & & 0.49 & $(-0.05,1.04)$ & 0.077 & & 0.54 & $(0.05,1.04)$ & 0.032 \\
\hline 4 or more NCDs & & 1.43 & $(0.82,2.03)$ & $<0.001$ & & 0.99 & $(0.48,1.51)$ & $<0.001$ \\
\hline Physical functioning score (FY $z$-score) & 194 & & & & 194 & & & \\
\hline 1 NCDs & & 0.03 & $(-0.37,0.43)$ & 0.889 & & -0.11 & $(-0.51,0.28)$ & 0.563 \\
\hline 2 NCDs & & 0.11 & $(-0.32,0.54)$ & 0.623 & & -0.33 & $(-0.74,0.08)$ & 0.115 \\
\hline 3 NCDs & & -0.30 & $(-0.89,0.29)$ & 0.320 & & -0.46 & $(-1.00,0.07)$ & 0.089 \\
\hline 4 or more NCDs & & -1.01 & $(-1.64,-0.37)$ & 0.002 & & -0.59 & $(-1.12,-0.06)$ & 0.029 \\
\hline & $N$ & Odds ratio & $95 \% \mathrm{CI}$ & $p$-value & $N$ & Odds ratio & $95 \% \mathrm{CI}$ & $p$-value \\
\hline Tandem stand $(<10 \mathrm{~s})$ & 204 & & & & 209 & & & \\
\hline 1 NCDs & & 0.44 & $(0.14,1.39)$ & 0.164 & & 0.41 & $(0.14,1.16)$ & 0.093 \\
\hline 2 NCDs & & 1.15 & $(0.40,3.34)$ & 0.792 & & 1.01 & $(0.40,2.57)$ & 0.986 \\
\hline 3 NCDs & & 1.72 & $(0.43,6.82)$ & 0.439 & & 1.42 & $(0.46,4.41)$ & 0.539 \\
\hline 4 or more NCDs & & 5.49 & $(1.43,21.01)$ & 0.013 & & 1.19 & $(0.38,3.75)$ & 0.767 \\
\hline Low physical functioning score $(<=9)$ & 179 & & & & 194 & & & \\
\hline $1 \mathrm{NCDs}$ & & 1.29 & $(0.55,3.02)$ & 0.556 & & 1.22 & $(0.51,2.93)$ & 0.651 \\
\hline 2 NCDs & & 1.40 & $(0.56,3.48)$ & 0.473 & & 1.13 & $(0.45,2.85)$ & 0.801 \\
\hline 3 NCDs & & 1.76 & $(0.50,6.25)$ & 0.382 & & 5.57 & $(0.98,31.59)$ & 0.052 \\
\hline 4 or more NCDs & & 1 & $(1.00,1.00)$ & & & 4.17 & $(0.82,21.37)$ & 0.086 \\
\hline
\end{tabular}

Adjusted for age, BMI, smoker status, alcohol consumption and social class

low physical functioning score $(\leq 9)$ was high in both sexes, even in a community-dwelling cohort such as ours, but significantly higher in women than men $(71.2 \%$ and $56.9 \%$, respectively). This is consistent with previous studies that have demonstrated that women have greater prevalence and incidence of mobility disability than men [20,21]. Our data have demonstrated in both sexes that there is an association between the number of NCDs and physical functioning score with a threshold effect seen at 4 or more self-reported NCDs. This is consistent with previous studies of multimorbidity [22]. Interestingly, in our population, physical functioning was generally not impaired in both sexes unless there were a relatively high number of four NCDs recorded. This is in contrast with the Longitudinal Aging Study Amsterdam, which showed decline in physical functioning was associated with a lower number of chronic diseases (adjusted ORs from 1.58 for 1 , to 4.05 for $\geq 3$ diseases) [23]. This observation may be partly a reflection of the 'healthy' responder bias in the HCS [24], whereby individuals who volunteered to partake in this research have a strong interest in their own health and therefore maintain activity despite multimorbidity. However, almost all the measurements of physical functioning are impaired if four or more NCDs are present. 
Table 3 Number of medications (categorical) as an explanatory variable for physical functioning outcomes, by sex

\begin{tabular}{|c|c|c|c|c|c|c|c|c|}
\hline & \multicolumn{4}{|c|}{ Men } & \multicolumn{4}{|c|}{ Women } \\
\hline & $N$ & $\begin{array}{l}\text { Regression } \\
\text { coefficient }\end{array}$ & $95 \% \mathrm{CI}$ & $p$-value & $N$ & $\begin{array}{l}\text { Regression } \\
\text { coefficient }\end{array}$ & $95 \% \mathrm{CI}$ & $p$-value \\
\hline Gait speed (FY z-score) & 196 & & & & 202 & & & \\
\hline $1-2$ medications & & -0.15 & $(-0.72,0.43)$ & 0.612 & & 0.17 & $(-0.36,0.69)$ & 0.532 \\
\hline $3-5$ medications & & -0.07 & $(-0.62,0.48)$ & 0.804 & & -0.48 & $(-0.99,0.04)$ & 0.068 \\
\hline 6 or more medications & & -0.39 & $(-0.95,0.17)$ & 0.173 & & -0.61 & $(-1.13,-0.09)$ & 0.021 \\
\hline Timed up-and-go (FY $z$-score) & 192 & & & & 200 & & & \\
\hline $1-2$ medications & & 0.10 & $(-0.44,0.63)$ & 0.725 & & 0.07 & $(-0.46,0.61)$ & 0.785 \\
\hline $3-5$ medications & & 0.17 & $(-0.34,0.69)$ & 0.509 & & 0.31 & $(-0.21,0.84)$ & 0.240 \\
\hline 6 or more medications & & 0.47 & $(-0.06,0.99)$ & 0.081 & & 0.62 & $(0.10,1.15)$ & 0.021 \\
\hline Chair rises (FY z-score) & 185 & & & & 185 & & & \\
\hline $1-2$ medications & & -0.43 & $(-0.97,0.12)$ & 0.125 & & -0.32 & $(-0.90,0.26)$ & 0.271 \\
\hline $3-5$ medications & & -0.24 & $(-0.77,0.28)$ & 0.360 & & -0.10 & $(-0.66,0.46)$ & 0.727 \\
\hline 6 or more medications & & 0.00 & $(-0.53,0.54)$ & 0.989 & & 0.41 & $(-0.16,0.99)$ & 0.156 \\
\hline Physical functioning score (FY z-score) & 194 & & & & 194 & & & \\
\hline $1-2$ medications & & 0.15 & $(-0.47,0.76)$ & 0.641 & & 0.19 & $(-0.41,0.80)$ & 0.530 \\
\hline $3-5$ medications & & -0.01 & $(-0.60,0.57)$ & 0.966 & & -0.02 & $(-0.61,0.58)$ & 0.954 \\
\hline 6 or more medications & & -0.28 & $(-0.88,0.32)$ & 0.365 & & -0.54 & $(-1.14,0.05)$ & 0.075 \\
\hline & $N$ & Odds ratio & $95 \% \mathrm{CI}$ & $p$-value & $N$ & Odds ratio & $95 \% \mathrm{CI}$ & $p$-value \\
\hline Tandem stand $(<10 \mathrm{~s})$ & 204 & & & & 209 & & & \\
\hline $1-2$ medications & & 1.98 & $(0.21,18.62)$ & 0.552 & & 1.09 & $(0.19,6.18)$ & 0.921 \\
\hline $3-5$ medications & & 3.56 & $(0.43,29.74)$ & 0.242 & & 0.85 & $(0.15,4.70)$ & 0.851 \\
\hline 6 or more medications & & 4.51 & $(0.54,37.61)$ & 0.164 & & 2.35 & $(0.45,12.23)$ & 0.310 \\
\hline Low physical functioning score $(<=9)$ & 194 & & & & 194 & & & \\
\hline $1-2$ medications & & 0.69 & $(0.19,2.46)$ & 0.569 & & 0.62 & $(0.16,2.38)$ & 0.483 \\
\hline 3-5 medications & & 1.11 & $(0.33,3.70)$ & 0.865 & & 0.91 & $(0.24,3.43)$ & 0.894 \\
\hline 6 or more medications & & 1.56 & $(0.45,5.40)$ & 0.482 & & 3.58 & $(0.84,15.29)$ & 0.085 \\
\hline
\end{tabular}

Adjusted for age, BMI, smoker status, alcohol consumption and social class

We also explored how the number of medications and medicated systems impacted upon physical functioning and found an association with gait speed and timed up-and-go tests in women. It has been well established in previous studies that polypharmacy is more common in women than men [25] and our findings support this. Few studies have explored how sex differences influence the impact of polypharmacy on physical function but an association between polypharmacy and impaired physical functioning in women is consistent with previous studies; the Women's Health Initiative Observational Study (WHI) in the United States showed a risk ratio of incident disability of 1.95 (1.54-2.46) when comparing $\geq 5$ with $0-5$ medications [26] and an earlier study encompassing community-dwelling women over 65 years of age in Maryland, USA demonstrated an association between impaired physical activities and over-thecounter and prescription medicines [27]. A previous study by Gnjidic and colleagues looking at older men in Sydney, Australia, enrolled in the Concord Health and Aging in Men
Project, did demonstrate an association between polypharmacy and physical function in men [28], which we did not observe in our cohort. A possible explanation as to why polypharmacy is associated with poorer physical function in women but not men in our cohort are sex differences in the type and severity of NCDs. A higher proportion of women than men in our cohort reported osteoarthritis (43.4\% vs $33.8 \%)$ and rheumatoid arthritis (5.0\% and $4.5 \%)$ which are disorders whose detrimental impact on physical functioning is well documented [29]. Additionally, biological differences between men and women may play a role; it has previously been shown that the sex of the patient can have profound influences on drug metabolism, efficacy and therefore adverse effects [30]. These differences are likely to be secondary to sex-specific differences in body composition (e.g. proportion of body fat) and drug metabolising enzyme (e.g. cytochrome P450) activity [31]. Therefore, it is biologically plausible that the women in our cohort are more susceptible to the detrimental effects of polypharmacy on 
physical function and this is an important consideration in the clinical setting.

\section{Limitations and strengths}

The number of NCDs was low in both sexes compared with other studies $[4,5]$ but this may reflect a 'healthy' responder bias in the HCS [24] and was equal in men and women. Furthermore, our study population may not be representative of the wider UK population. However, we have previously demonstrated that this cohort is representative of the general population with regard to body build and lifestyle factors, therefore suggesting that selection bias was minimal [24]. As to be expected with all studies of this nature there was some missing data; however, in the current study this was low (ranging from 0 to $13.5 \%$ for each variable). This study used a simple question to record NCDs-it did not consider duration or severity of the illness, nor did we attempt to validate it. Furthermore, the questionnaire did not address whether a participant had subsequently fully recovered from a past illness which may therefore no longer adversely affect their physical functioning. Future studies are therefore indicated to address how the severity and duration of illness may impact physical function. However, the specific purpose of the study was to assess whether such analysis might be predictive of low physical function-as such, it could be useful as a simple self-administered screening tool in clinical care.

\section{Conclusions}

In this study, self-report of 4 or more NCDs was associated with an increased risk of poor physical function, an outcome which has previously been associated with adverse clinical sequelae. The study was community based, rather than sited in a hospital outpatient setting, increasing the generalizability of our observations. This observation may be useful for clinicians caring for older adults in a community setting and may lead to the development of a simple screening tool for poor physical functioning.

Funding This work was funded by the Medical Research Council.

\section{Compliance with ethical standards}

Conflict of interest Professor Cyrus Cooper has received lecture fees and honoraria from Amgen, Danone, Eli Lilly, GSK, Kyowa Kirin, Medtronic, Merck, Nestlé, Novartis, Pfizer, Roche, Servier, Shire, Takeda and UCB outside of the submitted work. Professor Elaine Dennison has received speaker honoraria from UCB and Pfizer. Author Michael Clynes has received support for attending conferences from UCB, Pfizer and Eli Lily.
Statement of human and animal rights All procedures performed in studies involving human participants were in accordance with the ethical standards of the Hertfordshire Research Ethics Committee, reference number 10/h0311/59, and with the 1964 Helsinki declaration and its later amendments or comparable ethical standards.

Informed consent All participants provided informed consent prior to participation in this study.

Open Access This article is licensed under a Creative Commons Attribution 4.0 International License, which permits use, sharing, adaptation, distribution and reproduction in any medium or format, as long as you give appropriate credit to the original author(s) and the source, provide a link to the Creative Commons licence, and indicate if changes were made. The images or other third party material in this article are included in the article's Creative Commons licence, unless indicated otherwise in a credit line to the material. If material is not included in the article's Creative Commons licence and your intended use is not permitted by statutory regulation or exceeds the permitted use, you will need to obtain permission directly from the copyright holder. To view a copy of this licence, visit http://creativecommons.org/licenses/by/4.0/.

\section{References}

1. Prince MJ, Wu F, Guo Y et al (2015) The burden of disease in older people and implications for health policy and practice. Lancet 385:549-562. https://doi.org/10.1016/s0140-6736(14)61347-7

2. Duffield SJ, Ellis BM, Goodson N et al (2017) The contribution of musculoskeletal disorders in multimorbidity: implications for practice and policy. Best Pract Res Clin Rheumatol 31:129-144. https://doi.org/10.1016/j.berh.2017.09.004

3. Parreira PCS, Maher CG, Ferreira ML et al (2017) A longitudinal study of the influence of comorbidities and lifestyle factors on low back pain in older men. Pain 158:1571-1576. https://doi. org/10.1097/j.pain.0000000000000952

4. Bayliss EA, Ellis JL, Steiner JF (2007) Barriers to self-management and quality-of-life outcomes in seniors with multimorbidities. Ann Fam Med 5:395-402. https://doi.org/10.1370/afm.722

5. Fortin M, Bravo G, Hudon C et al (2005) Prevalence of multimorbidity among adults seen in family practice. Ann Fam Med 3:223-228. https://doi.org/10.1370/afm.272

6. Enderlin C, Rooker J, Ball S et al (2015) Summary of factors contributing to falls in older adults and nursing implications. Geriatric Nurs 36:397-406. https://doi.org/10.1016/j.gerin urse.2015.08.006

7. Curtis EM, Moon RJ, Dennison EM et al (2016) Recent advances in the pathogenesis and treatment of osteoporosis. Clin Med 16:360-364. https://doi.org/10.7861/clinmedici ne. 16-4-360

8. Cruz-Jentoft AJ, Baeyens JP, Bauer JM et al (2010) Sarcopenia: European consensus on definition and diagnosis: report of the European Working Group on Sarcopenia in older people. Age Ageing 39:412-423. https://doi.org/10.1093/ageing/afq034

9. Fielding RA, Vellas B, Evans WJ et al (2011) Sarcopenia: an undiagnosed condition in older adults. Current consensus definition: prevalence, etiology, and consequences. International working group on sarcopenia. J Am Med Dir Assoc 12:249-256. https://doi.org/10.1016/j.jamda.2011.01.003

10. Guralnik JM, Ferrucci L, Simonsick EM et al (1995) Lowerextremity function in persons over the age of 70 years as a predictor of subsequent disability. N Engl J Med 332:556-561. https://doi.org/10.1056/nejm199503023320902 
11. Penninx BW, Ferrucci L, Leveille SG et al (2000) Lower extremity performance in nondisabled older persons as a predictor of subsequent hospitalization. J Gerontol A Biol Sci Med Sci 55:M691-697

12. Fortin M, Lapointe L, Hudon C et al (2004) Multimorbidity and quality of life in primary care: a systematic review. Health Qual life Outcomes 2:51. https://doi.org/10.1186/1477-7525-2-51

13. Wei MY, Kabeto MU, Langa KM et al (2018) Multimorbidity and physical and cognitive function: performance of a new multimorbidity-weighted index. J Gerontol A Biol Sci Med Sci 73:225-232. https://doi.org/10.1093/gerona/glx114

14. Jones J, Jones GD, Thacker M et al (2017) Physical activity interventions are delivered consistently across hospitalized older adults but multimorbidity is associated with poorer rehabilitation outcomes: a population-based cohort study. J Eval Clin Pract 23:1469-1477. https://doi.org/10.1111/jep.12833

15. Moen K, Ormstad H, Wang-Hansen MS et al (2018) Physical function of elderly patients with multimorbidity upon acute hospital admission versus 3 weeks post-discharge. Disabil Rehabil 40:1280-1287. https://doi.org/10.1080/09638288.2017.1294211

16. George C, Verghese J (2017) Polypharmacy and gait performance in community-dwelling older adults. J Am Geriatr Soc 65:20822087. https://doi.org/10.1111/jgs.14957

17. Ishizaki T, Kobayashi E, Fukaya T et al (2019) Association of physical performance and self-rated health with multimorbidity among older adults: results from a nationwide survey in Japan. Arch Gerontol Geriatr 84:103904. https://doi.org/10.1016/j.archg er.2019.103904

18. Abbatecola AM, Cherubini A, Guralnik JM et al (2009) Plasma polyunsaturated fatty acids and age-related physical performance decline. Rejuvenation Res 12:25-32. https://doi.org/10.1089/ rej.2008.0799

19. da Camara SM, Alvarado BE, Guralnik JM et al (2013) Using the short physical performance battery to screen for frailty in young-old adults with distinct socioeconomic conditions. Geriatr Gerontol Int 13:421-428. https://doi.org/10.111 1/j.1447-0594.2012.00920.x

20. Bannerman E, Miller MD, Daniels LA et al (2002) Anthropometric indices predict physical function and mobility in older Australians: the Australian longitudinal study of ageing. Public Health Nutr 5:655-662. https://doi.org/10.1079/phn2002336

21. Guallar-Castillon P, Sagardui-Villamor J, Banegas JR et al (2007) Waist circumference as a predictor of disability among older adults. Obesity 15:233-244. https://doi.org/10.1038/oby.2007.532
22. Kadam UT, Croft PR (2007) Clinical multimorbidity and physical function in older adults: a record and health status linkage study in general practice. Fam Pract 24:412-419. https://doi.org/10.1093/ fampra/cmm049

23. Kriegsman DM, Deeg DJ, Stalman WA (2004) Comorbidity of somatic chronic diseases and decline in physical functioning: the longitudinal aging study Amsterdam. J Clin Epidemiol 57:55-65. https://doi.org/10.1016/s0895-4356(03)00258-0

24. Syddall HE, Aihie Sayer A, Dennison EM et al (2005) Cohort profile: the Hertfordshire cohort study. Int J Epidemiol 34:12341242. https://doi.org/10.1093/ije/dyi127

25. Bijani A, Hasanjani Roshan AR, Yazdanpour S et al (2014) Are older women likely to use medicines than older men? (Results from AHAP study). Caspian J Intern Med 5:77-81

26. Rosso AL, Eaton CB, Wallace R et al (2013) Geriatric syndromes and incident disability in older women: results from the women's health initiative observational study. J Am Geriatr Soc 61:371379. https://doi.org/10.1111/jgs.12147

27. Cadigan DA, Magaziner J, Fedder DO (1989) Polymedicine use among community resident older women: how much a problem? Am J Public Health 79:1537-1540. https://doi.org/10.2105/ ajph.79.11.1537

28. Gnjidic D, Hilmer SN, Blyth FM et al (2012) Polypharmacy cutoff and outcomes: five or more medicines were used to identify community-dwelling older men at risk of different adverse outcomes. J Clin Epidemiol 65:989-995. https://doi.org/10.1016/j. jclinepi.2012.02.018

29. Clynes MA, Jameson KA, Edwards MH et al (2019) Impact of osteoarthritis on activities of daily living: does joint site matter? Aging Clin Exp Res 31:1049-1056. https://doi.org/10.1007/s4052 0-019-01163-0

30. Lie MR, Kreijne JE, van der Woude CJ (2017) Sex is associated with adalimumab side effects and drug survival in patients with Crohn's disease. Inflamm Bowel Dis 23:75-81. https://doi. org/10.1097/mib.0000000000000981

31. Lu JF, Bruno R, Eppler S et al (2008) Clinical pharmacokinetics of bevacizumab in patients with solid tumors. Cancer Chemother Pharmacol 62:779-786. https://doi.org/10.1007/s0028 0-007-0664-8

Publisher's Note Springer Nature remains neutral with regard to jurisdictional claims in published maps and institutional affiliations. 